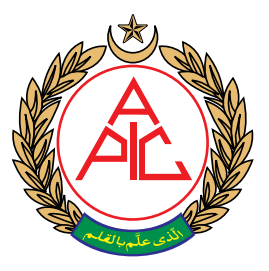

National Cancer Institute, Cairo University, Cairo (Egypt)

Correspondence: Hossam Zarif Hanna, National Cancer Institute, Cairo University, Cairo (Egypt);

Mobile: 20 01002412343; E-mail: hossam zarif@yahoo.com

Received \& Reviewed:

16, 21 August 2019.

Accepted: 28 August 2019

\title{
Effectiveness of multimodal preemptive analgesia in major pediatric abdominal cancer surgery
}

\author{
Hossam Zarif Ghobrial, Ehab Hanafy Shaker
}

\begin{abstract}
Objective: evaluate efficacy of combining multimodal analgesia and local anesthetic infiltration compared with caudal analgesia among pediatric patients undergoing major abdominal pediatric cancer surgery

Methodology: This randomized controlled pilot study was carried out at postoperative care unit of our institution. This pilot study enrolled 90 children ASA I and II with cancer scheduled for major abdominal surgery through a midline incision. Intervention: patients were randomly divided into three equal groups. The morphine group received IV morphine at a dose of $0.1 \mathrm{mg} / \mathrm{kg}$ after induction of anesthesia. The caudal group underwent caudal block. The multimodal group received paracetamol, ketorolac and ketamine infusion, with local wound infiltration of levobupivacaine before skin incision and at the end of surgery. After surgery, all patients were maintained on PCA morphine postoperatively. Primary outcome measure was total postoperative morphine consumption. The secondary endpoints were VAS score for pain, the time to first PCA bolus, and the number of PCA doses.
\end{abstract}

Results: that there were no between-group differences in the baseline characteristics of the participants. The three analgesic modalities provided adequate pain relief for up to $24 \mathrm{~h}$. The multimodal and caudal groups did not significantly differ in terms of total morphine consumption $(p=0.521)$, time to first analgesic bolus $(p=0.136)$, or the number of total and active PCA boluses ( $p=0.260$ and $p=0.904$, respectively). Both groups were superior to the morphine group regarding morphine consumption, time to first analgesic bolus, and the number of total and active PCA boluses

Conclusion: Preemptive multimodal analgesia and caudal block offered comparable efficacy in the target population.

Trial registration: clinicaltrial.gov with no. NCT03580980.

Key words: Multimodal; Analgesia; PCA; Pediatric; Cancer; Morphine.

Citation: Ghobrial HZ, Shaker EH. Effectiveness of multimodal preemptive analgesia in major pediatric abdominal cancer surgery. Anaesth pain \& intensiv care 2019;23(3):256-262

\section{INTRODUCTION}

In pediatric patients, pain is one of the poorly understood, under-diagnosed, and under-treated medical problem. ${ }^{1}$ If left uncontrolled, pain may have a bad effect on all aspects of life as it is not only a sensation but it also has emotional, cognitive, and behavioral components. Untreated pain in pediatric patients can be a significant cause of morbidity following surgical trauma. ${ }^{2}$

Surgical trauma initiates multiple physiologic mechanisms that cause postoperative pain, which comprises nociceptive, inflammatory, and neuropathic components. ${ }^{1}$ Inadequate relief of postoperative pain 
leads to substantial morbidity, delayed recovery, and mortality. ${ }^{2}$ Despite the development of new drugs and analgesic techniques, up to $40 \%$ of all hospitalized children-especially those undergoing surgery-experience moderate to severe pain. ${ }^{3}$ Adverse reactions to medications used for postoperative pain management (e.g. opioids) frequently occur, and include pruritus, nausea, and vomiting. ${ }^{4}$ The incidence of opioid-related respiratory depression is $0.11 \%-0.41 \% .5,6$

Regional anesthesia was suggested as an alternative to opioid-based analgesia among pediatric patients. Caudal epidural analgesia is a relatively safe and simple technique for postoperative pain management in this population. However, adverse effects related to the technique of catheter placement or systemic toxicity of the local anesthetic have been reported. Also the short duration of action of single-shot caudal block is its main disadvantage even with using longacting local aesthetics as bupivacaine. ${ }^{7}$

There are various modalities for pain control in abdominal surgeries that include drugs, local anesthetic infiltration, and peripheral nerve blocks. ${ }^{8}$ Combining drug as ketamine, Non-steroidal antiinflammatory drugs (NSAID), and paracetamol in multimodal analgesic approaches can reduce perioperative pain with the benefit of their opioidsparing effect. ${ }^{9}$ Preemptive multimodal analgesia uses a combination of delivery routes and variable time points of administration to maximize outcomes in the treatment of acute postoperative pain. ${ }^{10}$ The main idea for this technique is the producing sufficient analgesia by the synergistic effects between different analgesic modalities that act by different mechanisms at different sites in the nervous system, which helps in the reduction of doses of each drug and therefore decreases the occurrence of side effects from each medication used for postoperative pain management. ${ }^{11}$

Therefore, we conducted a prospective randomized controlled pilot study to evaluate the efficacy of combining preemptive multimodal analgesia and local anesthetic infiltration compared with preemptive caudal analgesia or morphine patientcontrolled analgesia
(PCA) among pediatric patients undergoing major abdominal cancer surgery.

\section{METHODOLOGY}

This prospective randomized controlled study was conducted at Children Cancer Hospital Egypt from March 2015 to December 2018 after approval of the Hospital Scientific Committee (SMAC) and Hospital Review Board and National Cancer Institute approval no: 2010013014.3. The study was registered at clinicaltrial.gov with no. NCT03580980. The inclusion criteria were ASA I or II, age 7-12 years, male or female, and major abdominal surgery with a midline incision. The exclusion criteria were a history of mental retardation or delayed development that could interfere with pain intensity assessment; known or suspected allergy to any administered drugs; active renal disease (creatinine clearance $<50$ $\mathrm{ml} / \mathrm{min}$ ), hepatic disease (liver enzymes more than 10 -fold); respiratory disease $\left(\mathrm{SpO}_{2}<92 \%\right.$ on room air); or cardiac disease (ejection fraction $<50 \%$ ). During the preoperative assessment, all participants were educated on how to use the A Visual Analogue Scale (VAS) to evaluate their pain, and on how to use the PCA pump to alleviate their pain. Uncooperative children were excluded from the study. Written informed consent was obtained from the parents or legal guardians of the participants.

\section{Anesthetic Technique:}

The patients were transferred to the operating

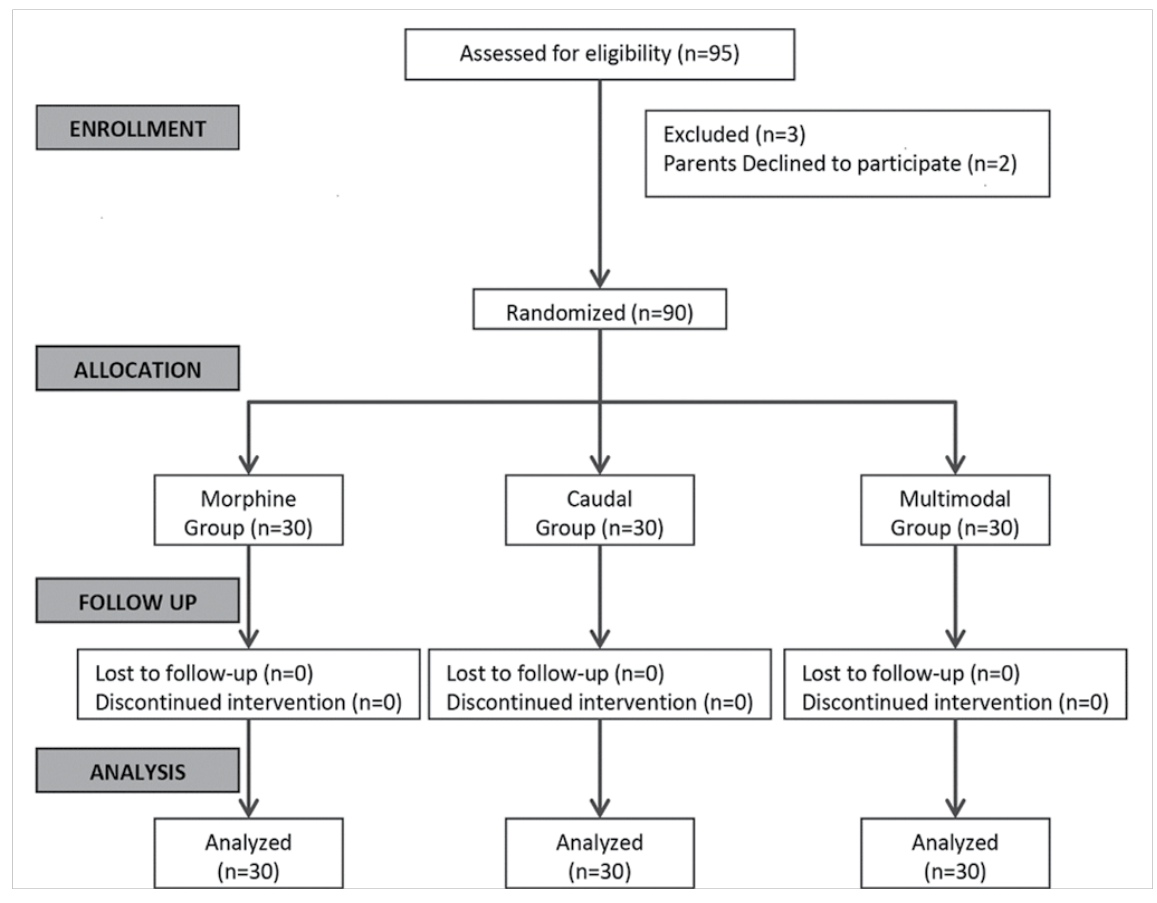

Figure1: Consort diagram 
theater after sedation with intravenous (IV) midazolam $(0.1 \mathrm{mg} / \mathrm{kg})$ in the preoperative holding area. Preoxygenation with $100 \% \mathrm{O}_{2}$ for $3 \mathrm{~min}$ was applied to all patients. Noninvasive monitoring was incorporated into the anesthesia workstation (Zeus ${ }^{\circledR}$, Dräger Medical, Lübeck, Germany) and included blood pressure, ECG, pulse oximetry $\left(\mathrm{SpO}_{2}\right)$, a nasopharyngeal temperature probe, and a peripheral nerve stimulator. Anesthesia was standardized for all patients. Anesthesia was induced with IV propofol (3 $\mathrm{mg} / \mathrm{kg})$, fentanyl $(2 \mu \mathrm{g} / \mathrm{kg})$, and rocuronium $(0.6 \mathrm{mg} /$ $\mathrm{kg}$ ) to facilitate endotracheal intubation. All patients were mechanically ventilated by the anesthesia machine (Zeus ${ }^{\circledR}$, Dräger Medical, Lübeck, Germany) using the auto control mode to maintain expired sevoflurane at $2 \%$ and inspired oxygen at $40 \%$. The tidal volume was set at $7 \mathrm{~mL} / \mathrm{kg}$, and the respiratory rate was adjusted according to the patient's age to maintain an end-tidal $\mathrm{CO}_{2}\left(\mathrm{EtCO}_{2}\right)$ of 30-35 $\mathrm{mmHg}$.

Using a computer-generated randomization list, the patients were randomly allocated into one of three groups (30 patients per group). The morphine group acted as the control group and included patients who received IV morphine at a dose of $0.1 \mathrm{mg} / \mathrm{kg}$ after induction of anesthesia. The caudal group included patients who received preemptive caudal analgesia. After induction of anesthesia, patients in the caudal group were placed in the lateral position and received a caudal epidural block using $0.125 \%$ levobupivacaine
(Chirocaine, Abbott Laboratories) delivered at a dose of $1.1 \mathrm{ml} / \mathrm{kg}$ plus morphine administered at a dose of $0.02 \mathrm{mg} / \mathrm{kg}$, with a maximum volume of $20 \mathrm{ml}$. Patients in the preemptive multimodal group received infusion of paracetamol $10 \mathrm{mg} / \mathrm{kg}$ over $10 \mathrm{~min}$ and ketamine $0.5 \mathrm{mg} / \mathrm{kg}$ bolus followed by ketorolac $1 \mathrm{mg} /$ $\mathrm{kg}$ infusion over $10 \mathrm{~min}$. Local anesthetic infiltration of the wound was performed by the surgeon one minute before the skin incision and at the end of surgery using $0.125 \%$ levobupivacaine, with a total maximum dose of $3 \mathrm{mg} / \mathrm{kg}$.

The muscle relaxant was reversed at the end of surgery using $4 \mathrm{mg} / \mathrm{kg}$ of sugammadex when TOF was greater than $80 \%$. Patients were extubated when the respiratory function was found to be adequate (according to age, tidal volume $>6 \mathrm{ml} /$ $\mathrm{kg}$, and $\mathrm{SpO}_{2}$ maintained above $95 \%$ on $\mathrm{FiO}_{2}<$ $50 \%$ ); hemodynamics were stable, and upper airway reflexes were fully recovered. Systolic blood pressure, diastolic blood pressure, heart rate, and oxygen saturation (by pulse oximetry) were recorded every $15 \mathrm{~min}$ intraoperatively and in the Post-Anesthesia Care Unit (PACU) and every $6 \mathrm{~h}$ for a period of $24 \mathrm{~h}$. All data were recorded using an electronic anesthesia record (Cerner Millennium software, USA). In the postoperative period, all patients were maintained on PCA (IVAC ${ }^{\mathrm{TM}}$ PCAM $^{\mathrm{TM}}$ syringe pump, BD, USA) morphine with a bolus of $20 \mu \mathrm{g} / \mathrm{kg}$ and lockout intervals of $10 \mathrm{~min}$.
Table 1: Baseline characteristics of the three analgesic groups

\begin{tabular}{|c|c|c|c|c|}
\hline Parameter & $\begin{array}{c}\text { Morphine } \\
\text { Group }(n=30)\end{array}$ & $\begin{array}{l}\text { Caudal Group } \\
\qquad(n=30)\end{array}$ & $\begin{array}{l}\text { Multimodal } \\
\text { Group }(n=30)\end{array}$ & $\mathrm{p}$ value \\
\hline Age (years) & $9.0 \pm 1.5$ & $9.9 \pm 1.5$ & $9.8 \pm 2.0$ & 0.104 \\
\hline Sex (male/female) & $13 / 17$ & $12 / 18$ & $14 / 16$ & 0.097 \\
\hline Weight (kg) & $20.4 \pm 6.2$ & $22.6 \pm 4.2$ & $21.1 \pm 5.7$ & 0.299 \\
\hline Height (cm) & $115.9 \pm 12.9$ & $120.7 \pm 8.6$ & $120.1 \pm 9.8$ & 0.166 \\
\hline \multicolumn{5}{|l|}{ Baseline hemodynamics } \\
\hline SBP (mmHg) & $98 \pm 5$ & $99 \pm 6$ & $98 \pm 4$ & 0.422 \\
\hline DBP (mmHg) & $62 \pm 6$ & $64 \pm 5$ & $65 \pm 5$ & 0.072 \\
\hline Heart rate & $106 \pm 11$ & $107 \pm 11$ & $108 \pm 10$ & 0.669 \\
\hline Oxygen saturation (\%) & $99 \pm 1$ & $99 \pm 1$ & $99 \pm 1$ & 0.425 \\
\hline Duration of surgery (min) & $186 \pm 26$ & $189 \pm 38$ & $194 \pm 24$ & 0.601 \\
\hline \multicolumn{5}{|l|}{ Type of surgery } \\
\hline $\begin{array}{l}\text { Cancer ovary } \\
\text { Intestinal obstruction } \\
\text { Retroperitoneal mass } \\
\text { Cancer bladder } \\
\text { Abdominal lymph node } \\
\text { biopsy }\end{array}$ & $\begin{array}{l}7 \\
7 \\
6 \\
4 \\
6\end{array}$ & $\begin{array}{l}9 \\
8 \\
5 \\
3 \\
3\end{array}$ & $\begin{array}{l}6 \\
6 \\
7 \\
5 \\
6\end{array}$ & $\begin{array}{l}0.656 \\
0.829 \\
0.812 \\
0.749 \\
0.487\end{array}$ \\
\hline
\end{tabular}

The primary outcome measure was total morphine consumption during the postoperative period $(24 \mathrm{~h})$. The secondary endpoints were VAS score for pain at $6,12,18$, and $24 \mathrm{~h}$ after surgery; the time to first PCA bolus; and the number of total and active PCA pushes. All postoperative data collected by acute pain service team members who were blinded to the study

\section{Sample Size Estimation:}

This study was designed as a randomized pilot study. The primary outcome variable was the total morphine consumption during the 24 postoperative hours. We hypothesized a small effect size of the multimodal approach. Thus, if the effective size is set at 0.25 , the calculated number of samples required was 30 patients per group using an $80 \%$ upper confidence limit inflation method according to Whitehead et al. ${ }^{12}$ 
Table 2: Postoperative analgesic profile in the three studied groups

\begin{tabular}{|c|c|c|c|c|}
\hline Variables & $\begin{array}{c}\text { Morphine } \\
\text { Group }(n=30)\end{array}$ & $\begin{array}{l}\text { Caudal Group } \\
\qquad(n=30)\end{array}$ & $\begin{array}{l}\text { Multimodal } \\
\text { Group }(n=30)\end{array}$ & $\mathrm{p}$ value \\
\hline \multicolumn{5}{|l|}{ Postoperative VAS score } \\
\hline Immediate & $3(0-6)$ & $3(0-7)$ & $2(0-7)$ & 0.799 \\
\hline After $6 \mathrm{~h}$ & $3(0-5)$ & $4(0-6)$ & $4(0-7)$ & 0.723 \\
\hline After $12 \mathrm{~h}$ & $3(0-6)$ & $3(0-6)$ & $2(0-7)$ & 0.519 \\
\hline After $18 \mathrm{~h}$ & $3(0-6)$ & $4(0-6)$ & $3(1-5)$ & 0.580 \\
\hline After $24 \mathrm{~h}$ & $2(0-6)$ & $2(0-6)$ & $2(0-5)$ & 0.546 \\
\hline Number of PCA total boluses & $19 \pm 4^{\mathrm{a}}$ & $13 \pm 3^{b}$ & $12 \pm 3^{b}$ & $<0.001$ \\
\hline Number of PCA active boluses & $16 \pm 3^{a}$ & $10 \pm 2^{b}$ & $11 \pm 2^{b}$ & $<0.001$ \\
\hline Time to first bolus (min) & $66 \pm 16^{a}$ & $122 \pm 36^{b}$ & $107 \pm 29^{b}$ & $<0.001$ \\
\hline Total morphine consumption (mg) & $12 \pm 2^{\mathrm{a}}$ & $6 \pm 1^{b}$ & $6 \pm 1^{b}$ & $<0.001$ \\
\hline
\end{tabular}

Legend: VAS: Visual Analogue Scale Data are presented as median (range) or mean $\pm S D$ Groups with different superscript letters are significantly different

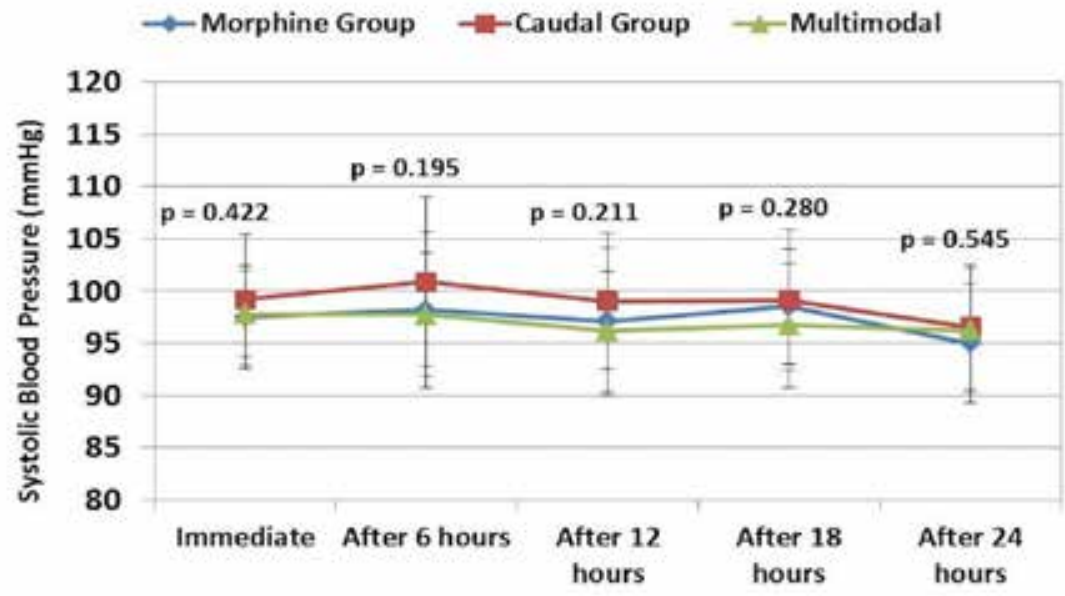

Figure 2: Comparative systolic blood pressure readings in three groups

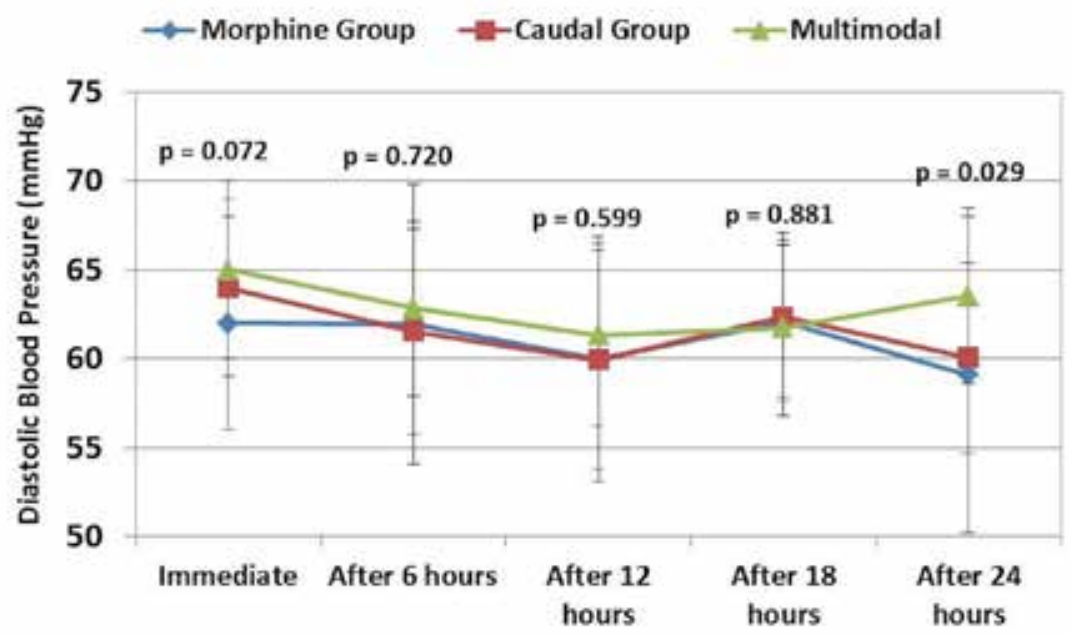

Figure 3: Comparative diastolic blood pressure readings in three groups

\section{Statistical Methods:}

Statistical analysis was performed using SPSS $\odot$ ) version 22 (IBM $\odot$ Corp., Armonk, NY, USA). The power of the test used for the primary outcome measure was estimated using $\mathrm{G} \star$ Power $\odot$ software version 3.1.9.2 (Institutfür Experimentelle Psychologie, Heinrich Heine Universität, Düsseldorf, Germany). Numerical data are expressed as the mean and standard deviation or median and range, as appropriate. Qualitative data are expressed as frequency and percentage. A chi-square test was used to examine the relationships between qualitative variables. For quantitative data, comparisons among the three groups were made using ANOVA or the Kruskal-Wallis test followed by the appropriate post hoc test. Comparisons of repeated measures were performed using the Friedman test followed by the Wilcoxon signed-ranks test. All tests were two-tailed. A p-value < 0.05 was considered statistically significant.

\section{RESULTS}

The baseline characteristics of the participants are shown in Table 1. No statistically significant between-group differences were found.

The multimodal analgesic modalities provided adequate relief of pain intensity for up to $24 \mathrm{~h}$ postoperatively. As shown in Table 2, the primary outcome measure (total morphine consumption) was comparable between the multimodal and caudal groups $(\mathrm{p}=0.521)$. By contrast, total morphine consumption was lower for each of these two groups when compared with the morphine group ( $\mathrm{p}<$ 0.001 for both comparisons).

Table 2 also outlines the secondary outcome measures. The VAS score was comparable among the 


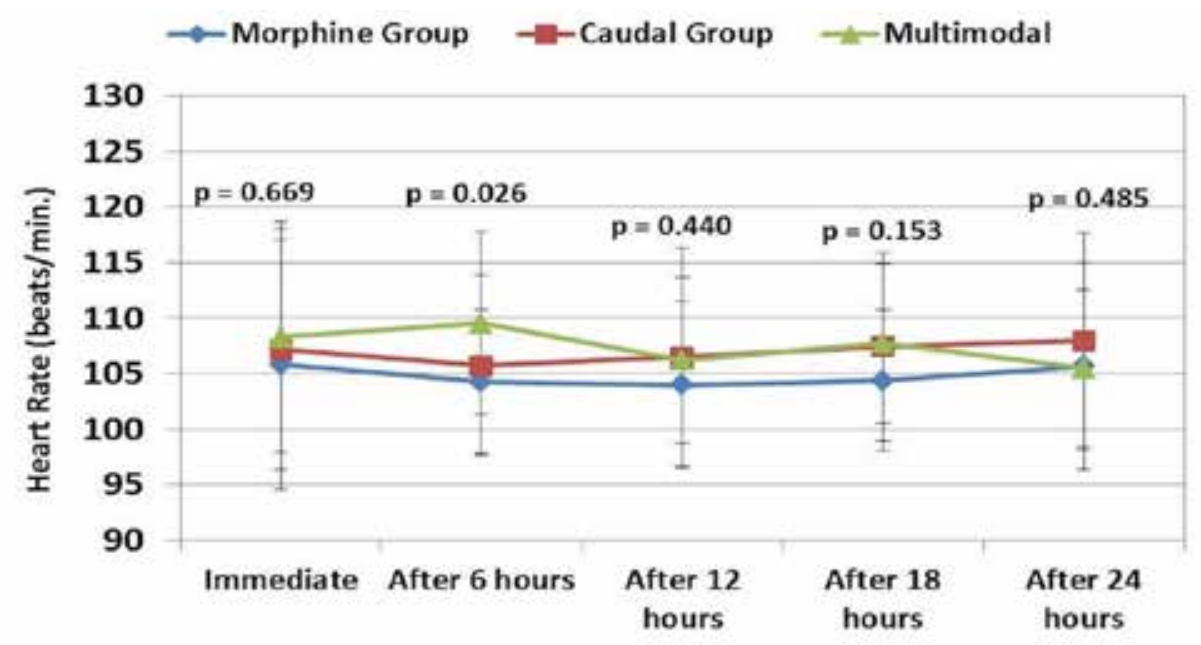

Figure 3: Comparative heart rate readings in three groups multimodal analgesia was associated with reduced total morphine consumption, prolonged analgesia, and lowered pain intensity when compared with the use of IV morphine with hemodynamic stability.

The search continues for an ideal analgesic modality in pediatric surgery that can provide safe and effective pain management that suits the age, clinical condition, and associated comorbidities of the patient. $^{13}$ Increased understanding of the mechanism of postoperative pain might aid the identification of such a modality. Postoperative pain is multifactorial; surgical trauma initiates multiple physiological mechanisms that cause pain with its nociceptive, inflammatory, and neuropathic components. ${ }^{1}$ Neurophysiologic and pharmacologic studies suggest that hyperalgesia of the incision region is mediated by sensitization of A $\delta$-fiber and C-fiber nociceptors. ${ }^{14}$ Other studies have demonstrated the role of $\alpha$-amino-3-hydroxy5-methyl-4-isoxazole-propionate (AMPA) / kainate ionotropic excitatory amino acid receptors in incision-induced pain, hyperalgesia, and spinal sensitization. ${ }^{15}$ A study using a rat model found that hypoxic conditions are present in deep tissue after surgical incisions. ${ }^{16}$ This finding supports an ischemic mechanism that could contribute to postoperative pain. ${ }^{17}$ Additionally, central neuronal sensitization might contribute to postoperative pain and hyperalgesia. ${ }^{18}$

Therefore, the use of multiple analgesic modalities seems to offer a good alternative to opioids for combating various sources of postoperative pain. This multimodal approach is intended to improve analgesia and reduce the adverse effects associated with analgesic medications. ${ }^{19}$ Prevention of pain among infants and children by using multimodal analgesia is effective in almost all cases and can be adapted for outpatients, patients undergoing major surgery, critically ill children, or patients who are younger than 12 years. $^{20}$

In the current study, components of preemptive multimodal analgesia included paracetamol, NSAID, and ketamine infusion with local anesthetic infiltration of the wound before incision and at the end of surgery. The other component was provided in the postoperative period as PCA morphine. Most 
investigators agreed with each of this five-component strategy. ${ }^{21,22}$ NSAIDs are proposed to attenuate the activation of peripheral nociceptors. Local anesthetics and ketamine can impede nociceptive transmission and processing through the dorsal horns. In addition, IV administration of opioids can ameliorate pain within the central nervous system..$^{23,24}$

We resorted to total morphine consumption as a more or less objective measure of analgesic efficacy. The age group of the present study participants (5-12 years) was suitable for the assessment of pain assessment using measures such as the VAS score. However, as the main postoperative analgesic method was PCA with maintaining VAS below 4, we could not rely on the VAS scores to compare the three groups.

Aiming to improve analgesia by preventing the onset of pain, we adopted the preemptive approach in this study. The concept of preemptive analgesia is still a controversial issue despite having been used for three decades. No consensus exists on its use among adults: many randomized clinical trials have reported equivocal evidence on the advantages of pre-incisional analgesic administration. ${ }^{25,26}$ Among children, evidence to either validate or disprove preemptive analgesia is limited.

Song et al. reported no significant advantage of preemptive analgesia using IV-PCA with fentanyl for postoperative analgesia among children undergoing corrective osteotomy. ${ }^{27}$ Another study concluded that caudal block with bupivacaine and midazolam provided better postoperative pain relief when applied before surgical incision than when it was given after surgical incision. ${ }^{28}$

The strength of the present study is that preemptive multimodal analgesia was as effective as a preemptive caudal block without any deleterious changes in the hemodynamics in the target group.

Nonetheless, some limitations of the present study should be highlighted. For example, the relatively small number of the studied patients, this study might open the way for further investigation regarding the use of combined techniques of multimodal analgesia with the preemptive caudal block among larger controlled multicenter trials.

\section{CONCLUSION}

In conclusion, we found that the type of analgesic modality used can determine the efficacy of preemptive analgesia among children undergoing major abdominal surgery, and that preemptive multimodal analgesia was as effective as a preemptive caudal block. The combined approach appears to be a good alternative to opioid-based analgesia; however, its use remains to be tested in a large cohort of pediatric patients.

Conflict of interest: None declared by the authors

Authors' contribution:

HZG: Conception, clinical work, data collection and writing the manuscript

EHS: Design, analysis, interpretation and final review

\section{REFERENCES}

1. Mathews L. Pain in children: neglected, unaddressed and mismanaged. Indian J Palliat Care. 2011;17(1):70-3.

2. Verghese ST, Hannallah RS. Acute pain management in children J Pain Res. 2010 Jul 15;3:105-23. [PubMed]

3. Hancı V, Yurtlu BS, Domi R, Shibata Y, Eyigör C. Acute postoperative pain control. Pain Res Manag. 2017; Article ID 7831014. DOI: 10.1155/2017/7831014

4. Wu CL, Naqibuddin M, Rowlingson AJ, Lietman SA, Jermyn RM, Fleisher LA. The effect of pain on health-related quality of life in the immediate postoperative period. Anesth

Analg. 2003;97(4):1078-85.

[PubMed] DOI: 10.1213/01. ane.0000081722.09164.d5

5. Kozlowski LJ, Kost-Byerly S, Colantuoni E, Thompson CB, Vasquenza KJ, Rothman SK, et al. Pain prevalence, intensity, assessment and management in a hospitalized pediatric population. Pain Manag Nurs Off $\mathrm{J}$ Am Soc Pain Manag Nurses. 2014;15: 22-35. D0I: https://doi. org/10.1016/i.pmn.2012.04.003

6. Smyth RL, Peak M, Turner MA, Nunn AJ, Williamson PR, Young $B$, Arnott J, et al. ADRIC: Adverse Drug Reactions In Children -a programme of research using mixed methods. Southampton (UK): NIHR Journals Library; 2014. http://www.ncbi.nlm. nih.gov/books/NBK262747/ (2014, accessed 23 April 2018). DOI: $10.3310 /$ pgfar02030

7. Howard RF, Lloyd-Thomas A, Thomas M, Williams DG, Saul $R$, Bruce $E$, et al. Nurse-controlled analgesia (NCA) following major surgery in 10,000 patients in a children's hospital. Paediatr Anaesth. 2010;20(2):126-34. [PubMed] DOI: 10.1111/j.1460$\underline{9592.2009 .03242 . x}$

8. West N, Nilforushan V, Stinson J, Ansermino JM, Lauder G. 
Critical incidents related to opioid infusions in children: a fiveyear review and analysis. Can J Anaesth. 2014;61(4): 31221. [PubMed] DOI: $10.1007 /$ s12630-013-0097-2

9. Tobias JD. Caudal epidural block: a review of test dosing and recognition of systemic injection in children: Anesth Analg. 2001;93(5):1156-61. [PubMed] DOI: $\quad 10.1097 / 00000539-$ 200111000-00018

10. Rosero EB, Joshi GP. Preemptive, preventive, multimodal analgesia: what do they really mean? Plast Reconstr Surg. 2014;134:8593. [PubMed] DOl: 10.1097/ PRS.0000000000000671

11. Brennan TJ, Taylor BK. Analgesic treatment before incision compared with treatment after incision provides no improvement in postoperative pain relief. J Pain. 2000;1 96-8.

12. Katz J, Schmid R, O'Lear G, Chan $V$, Halket E. Postoperative pain \& morphine are reduced by perioperative multimodal analgesia. Can J Anesth. 2006;53:26338.

13. McGreevy $\mathrm{K}$, Bottros MM, Raja SN. Preventing chronic pain following acute pain: risk factors, preventive strategies, and their efficacy. Eur $\mathrm{J}$ Pain Suppl. 2011;5(2):365-72. [PubMed] DOI: 10.1016/..euips.2011.08.013

14. Whitehead AL, Julious $S A$, Cooper CL, Campbell MJ. Estimating the sample size for a pilot randomised trial to minimise the overall trial sample size for the external pilot and main trial for a continuous outcome variable. Stat Methods Med Res. 2016;25(3):1057-
73. [PubMed] DOI: 10.1177/0962280215588241

15. Morton NS. The pain-free ward: myth or reality. Paediatr Anaesth. 2012;22(6):527-29. [PubMed] DOI: 10.1111/i.14609592.2012.03881.x

16. Pogatzki EM, Gebhart GF, Brennan TJ. Characterization of Adelta-and C-fibers innervating the plantar rat hindpaw one day after an incision. J Neurophysiol. 2002;87(2):721-31. [PubMed] DOI: 10.1152/in.00208.2001

17. Zahn PK, Umali E, Brennan TJ. Intrathecal non-NMDA excitatory amino acid receptor antagonists inhibit pain behaviors in a rat model of postoperative pain. Pain. 1998 Feb;74(2-3):213-23. [PubMed] D0I: $10.1016 / \mathrm{s} 0304-$ 3959(97)00181-4

18. Kang $S$, Lee D, Theusch BE, Arpey CJ, Brennan TJ. Wound hypoxia in deep tissue after incision in rats. Wound Repair Regen. 2013 Sep;21(5):730-9.

19. Kang $S$, Lee $D$, Theusch BE, Arpey CJ, Brennan TJ. Wound hypoxia in deep tissue after incision in rats. Wound Repair Regen. 2013 Sep;21(5):730-9.

20. Wu CL, Raja SN. Treatment of acute postoperative pain. Lancet. 2011;377(9784):2215-25. [PubMed] D0l: 10.1016/S01406736(11)60245-6

21. Russell $P$, von Ungern-Sternberg BS, Schug SA. Perioperative analgesia in pediatric surgery. Curr Opin Anaesthesiol. 2013;26:4207. [PubMed] DOI: $10.1097 / \mathrm{ACO}$. 0b013e3283625cc8

22. Lönnqvist P-A, Morton NS. Postoperative analgesia in infants and children. $\mathrm{Br} \mathrm{J}$ Anaesth.
2005;95:59-68. [PubMed] DOl: 10.1093/bia/aei065

23. DeLeo JA. Basic science of pain. J Bone Joint Surg Am. 2006 Apr;88 Suppl 2:58-62. [PubMed] DOI: 10.2106/JBJS.E.01286

24. Yaster M. Multimodal analgesia in children. Eur $\mathrm{J}$ Anaesthesiol. 2010 0ct;27(10):851-7. [PubMed] DOI: 10.1097/EJA. 0b013e328338c4af

25. Coughlin SM, Karanicolas PJ, Emmerton-Coughlin HM, Kanbur B, Kanbur S, Colquhoun $\mathrm{PH}$.. Better late than never? Impact of local analgesia timing on postoperative pain in laparoscopic surgery: a systematic review and metaanalysis. Surg Endosc. 2010 Dec;24(12):316776. [PubMed] DOl: $10.1007 /$ s00464-010-1111-1

26. Ong CK, Lirk P, Seymour RA, Jenkins BJ. The efficacy of preemptive analgesia for acute postoperative pain management: a meta-analysis. Anesth Analg. 2005 Mar;100(3):75773. [PubMed] DOI: $10.1213 / 01$. ANE.00001444428.98767.0E

27. Song IK, Park YH, Lee JH, Kim JT, Choi IH, Kim HS. Randomized controlled trial on preemptive analgesia for acute postoperative pain management in children. Paediatr Anaesth. 2016 Apr;26(4):438-43. [PubMed] DOI: 10.1111/pan.12864

28. Hasani A, Soljakova M. Preemptive Analgesia in Children With Caudal Blocks, http://www. webmedcentral.com/ (2011, accessed 24 April 2018). [Free Full Text] 